Spurk, D., Hirschi, A., Dries, N. (2019). Antecedents and outcomes of objective versus subjective career success: Competing perspectives and future directions. Journal of Management, 45(1), 35-69. doi:10.1177/014920631878656

\title{
Antecedents and Outcomes of Objective versus Subjective Career Success: Competing Perspectives and Future Directions
}

\author{
Daniel M. Spurk ${ }^{* 1}$, Andreas Hirschi ${ }^{1}$, Nicky Dries ${ }^{2}$ \\ ${ }^{1}$ University of Bern \\ ${ }^{2}$ KU Leuven
}

\begin{abstract}
Author's Note
*Correspondence concerning this article should be addressed to Daniel Spurk, PhD, University of Bern, Department of Work and Organizational Psychology, Fabrikstrasse 8, 3012 Bern, Switzerland

Email:daniel.spurk@psy.unibe.ch
\end{abstract}

\section{Acknowledgements}

We want to express our gratitude to our respective research groups, which continuously provided helpful feedback on this paper. A special thanks goes out to Martina Selz for her help in the coding process and to Giverny De Boeck and Drew Mallory for their comments on the manuscript. Finally, we thank the anonymous reviewers for their constructive comments on earlier versions of the manuscript. 


\section{Abstract}

This review examines competing perspectives relating to (a) the range and prevalence of different theoretical approaches to the study of career success and (b) the need for a theoretically differentiated understanding of the antecedents of objective (OCS) versus subjective (SCS) career success. Furthermore, the review complements the assumption that OCS and SCS are only ultimate outcomes of careers, proposing instead that career success also acts as an antecedent to other career and life outcomes. Against the backdrop of an organizing resource management framework, we present and critically evaluate the results of a systematic analysis of the theoretical approaches used to empirically study the antecedents of OCS and SCS. Furthermore, we develop a taxonomy of outcomes of career success. Our review findings show a theoretical heterogeneity with some dominant theoretical approaches within research of antecedents of career success. Moreover, past research started to adopt different theoretical approaches when predicting OCS (e.g., approaches focusing on personal resources, such as human capital or [competitive] performance) versus SCS (e.g., approaches focusing on personal key resources, such as stable traits). Several types of career success outcomes were identified: withdrawal, career attitudes, health and well-being, reactions from the (work) environment, and self-concept. Based on these findings, we provide recommendations for how future research can make sense of the theoretical heterogeneity in career success research, how research on antecedents and outcomes can better account for the OCS/SCS distinction, and how future research can more rigorously integrate research on antecedents and outcomes of career success.

Keywords: objective career success; subjective career success; antecedents; outcomes; systematic review 


\section{Antecedents and Outcomes of Objective versus Subjective Career Success: Competing Perspectives and Future Directions}

Career success has been a focal research topic in management and applied psychology since the 1970s (Feldman \& Ng, 2007; Ng, Eby, Sorensen, \& Feldman, 2005; Sullivan \& Baruch, 2009). The question of what represents, predicts, and results from career success is of importance not only to individuals, but also to organizations as well (e.g., Arthur, Khapova, \& Wilderom, 2005; Hall \& Chandler, 2005; Heslin, Keating, \& Minbashian, in press). Empirical research on career success has been interested primarily in predicting success, especially inferring best practices for achieving it. Often-cited studies typically have examined how certain career strategies (e.g., frequent organizational moves, networking) can help people achieve success (e.g., De Janasz \& Forret, 2008); how different personal characteristics (e.g., personality traits, gender, race) are related to career success (e.g., Spurk \& Abele, 2011); how planned or unplanned life events (e.g., becoming a parent) might hinder the road to success (e.g., Valcour \& Ladge, 2008); and what makes people feel subjectively successful (e.g., Shockley, Ureksoy, Rodopman, Poteat, \& Dullaghan, 2016).

The distinction between objective career success (OCS) versus subjective career success (SCS) has received much attention in conceptual work, especially in terms of definition and measurement (e.g., Abele \& Spurk, 2009; Arthur et al., 2005; Gunz \& Heslin, 2005). Whereas OCS is defined as directly observable by others and measurable in a standardized way (Arthur et al., 2005; Gunz \& Heslin, 2005)—by weighing a person's career against societal norms concerning salary, job level, promotion history, or occupational prestige (Dries, Pepermans, Hofmans, \& Rypens, 2009) SCS is defined as the focal career actor's evaluation and experience of achieving personally meaningful career outcomes (Ng et al., 2005; Seibert, 2006; Shockley et al., 2016). SCS is typically measured as career satisfaction (Greenhaus, Parasuraman, \& Wormley, 1990; Seibert, Kraimer, Holtom, \& Pierotti, 2013) or perceived career success (Heslin, 2003; Turban \& Dougherty, 1994), and more recently as a multidimensional evaluation of career facets, such as growth and development, personal life, and authenticity (Shockley et al., 2016). The correlation between OCS and SCS reported in meta-analytical reviews typically has been small to moderate, ranging from .22 to .30 ( $\mathrm{Ng}$ et al., 2005) - with even smaller or non-significant correlations reported between indicators of OCS and specific SCS facets (Shockley et al., 2016).

Although a vast body of academic work on career success exists, competing perspectives can be identified in the literature that have, to date, not been systematically examined. First, the literature reveals competing perspectives on what are, or should be, the dominant theoretical approaches to explaining and predicting the attainment of career success. Existing reviews offer divergent assessments of which theoretical approaches have dominated past career (success) research (e.g., valence-instrumentality-expectancy models, the stress-coping paradigm, role theory, and network theory according to Feldman \& Ng, 2007; person-environment fit theories, life span career development theories, protean and boundaryless career models, and cognitive and social-cognitive theories, according to Wang \& Wanberg, 2017). These assessments, however, were based on subjective evaluations by the respective authors rather than on a systematic review of the literature. In addition to such assessments of the relative prevalence of different types of theoretical approaches, past reviews on (antecedents of) career success that have adopted a single theory as 
their review framework have also been theoretically diverse (e.g., mobility and embeddedness, Feldman \& Ng, 2007; contest and sponsored mobility, Ng \& Feldman, 2005). Unfortunately, the full range and prevalence of theoretical approaches to the study of career success, and the extent to which different theoretical approaches have been conceptually and empirically compared and contested in past research, remains unclear.

Second, although the literature is clear about OCS and SCS representing nomologically different facets of career success (e.g., Abele \& Spurk, 2009; Arthur et al., 2005; Gunz \& Heslin, 2005), competing perspectives are found regarding whether there is a need to develop a differentiated theoretical understanding of the attainment of OCS versus SCS. Consequently, which theories might be better suited to explain the attainment of OCS versus SCS, and which theories might apply to both success types equally, remains unclear. On the one hand, some reviews suggest that certain theoretical approaches might be better suited to explaining OCS (e.g., human capital theory; Feldman \& Ng, 2007; Ng et al., 2005) and others to explaining SCS (e.g., boundaryless career theory; Arthur et al., 2005). Such a view is supported by research on new careers that took off in the late 1990s and developed out of the assumption that the old, traditional-organizational career is dead-implying that SCS is a fully idiosyncratic evaluation that does not necessarily coincide with OCS (Hall \& Chandler, 2005). On the other hand, several recent articles have stated that many people still aspire to the hallmarks of the objectively successful, secure organizational career, and that this type of career might still be the most predictive of SCS (e.g., Dries \& Verbruggen, 2012; Rodrigues \& Guest, 2010). In line with this view, the same theoretical approaches have been applied to the explanation of both OCS and SCS (e.g., broaden-and-build theory, Boehm \& Lyubomirsky, 2008; conservation of resources theory, Ng \& Feldman, 2014a, b). Empirical studies in particular have often formulated identical hypotheses for OCS and SCS, using the same theoretical rationale for both (e.g., Bozionelos, 2004; De Vos, De Clippeleer, \& Dewilde, 2009).

Both competing perspectives hinder a systematic, structured, balanced, and theoretically concise approach to the study of antecedents of OCS and SCS. To examine these competing perspectives, we need a systematic review of the extent to which empirical research has, in fact, drawn upon diverse theoretical explanations and adopted the same or different theoretical approaches when examining predictors of OCS versus SCS — as well as a content-driven systematic analysis of the extent to which such a differentiation is desirable and necessary.

The existing literature has typically conceptualized OCS and/or SCS as the ultimate outcome of a career. However, some variables that are typically treated as antecedents of career success might just as well be outcomes (Ng \& Feldman, 2014a) - for instance, work-related self-efficacy beliefs (Spurk \& Abele, 2014). Indeed, career success can also be understood as an antecedent to other valuable life and career outcomes, such as organizational commitment, career calling perceptions, or well-being (Abele, Hagmaier, \& Spurk, 2016; Gao-Urhahn, Biemann, \& Jaros, 2016; Hall \& Chandler, 2005). Conversely, career success has been linked to negative consequences in terms of work-life conflict and personal failure (e.g., Baruch \& Vardi, 2016; Korman, Wittig-Berman, \& Lang, 1981), and even suicide, especially when achieved levels of success cannot be maintained 
(Duff \& Chan, 2014). Regrettably, potential positive or negative outcomes of OCS and SCS have not yet been reviewed in any systematic way.

To address these issues, we performed a systematic review of the quantitative career success literature organized within an integrative resource management framework (e.g., Hobfoll, Halbesleben, Neveu, \& Westman, 2018; Ten Brummelhuis \& Bakker, 2012), which allowed us to relate insights from quantitative empirical research to seminal conceptual, qualitative, and review articles on the antecedents and outcomes of career success (e.g., Arthur et al., 2005; Duff \& Chan, 2014; Feldman \& Ng, 2007; Gunz \& Heslin, 2005; Hall \& Chandler, 2005; Heslin et al., in press). Our review extends existing quantitative (e.g., $\mathrm{Ng}$ et al., 2005; Ng \& Feldman, 2014b) and qualitative reviews (e.g., Arthur et al., 2005; Boehm \& Lyubomirsky, 2008; Feldman \& Ng, 2007) of career success research in several ways. First, we developed a taxonomy of the different theoretical approaches used to explain the attainment of career success in past research, including an assessment of their prevalence. Additionally, we thoroughly reviewed empirical studies that explicitly compared and tested different theoretical approaches and related antecedent classes. In doing so, we have provided more structure and clarity to a theoretically heterogeneous field of research, and have included suggestions of how future research might navigate within, and better understand, this theoretical heterogeneity.

Second, we analyzed theoretical approaches to determine which have dominated research on OCS and SCS, respectively. In doing so, we have provided more clarity regarding if and how there has been different theoretical approaches applied to understand correlates of OCS versus SCS in existing research. A superordinate aim has been to draw conclusions about which theoretical approaches might be better suited to understand the attainment of OCS versus SCS. Based on this analysis, we will be able to show the extent to which the conceptual distinction between OCS and SCS has been translated into empirical research based on their respective antecedents, and provide suggestions for future research on the correlates and predictors of OCS and SCS as distinct, but related, constructs.

Third, we systematically reviewed work that has considered outcomes of career success. We have focused specifically on studies with designs that allow for stronger causal inference (e.g., longitudinal designs, change analysis, cross-lagged panel designs, experimental designs) to achieve more clarity about which variables should be considered antecedents versus outcomes of career success. We propose that to obtain a more comprehensive differentiated understanding of OCS and SCS, we must not only understand the underlying (and potentially different) theoretical assumptions about their antecedents, but also their outcomes. This analysis, thus, allows us to provide suggestions for future research on examining short- and long-term outcomes of career success.

\section{Review Framework}

\section{A Resource Management Perspective of Antecedents of Career Success}

To organize our systematic review, embed findings from empirical research, and connect research on antecedents and outcomes of career success theoretically, we drew on conservation of resources theory (COR; Hobfoll, 1989; Hobfoll et al., 2018) and associated resource taxonomies (e.g., Hobfoll, 2002; Ten Brummelhuis \& Bakker, 2012). Although COR is traditionally viewed as a theory that explains the emergence of and reaction to stress, it is increasingly applied as a more 
general motivational theory (Hobfoll et al., 2018). COR theory outlines the general principles by which resources function, change, and are managed to achieve favorable outcomes (Hobfoll et al., 2018). Within this current understanding, resources can be defined as any entity that helps people obtain personally valued objects or states (Halbesleben, Neveu, Paustian-Underdahl, \& Westman, 2014). As such, COR theory has been applied to explain college achievement (Feldman, Davidson, \& Margalit, 2015) and job performance (Park, O'Rourke, \& O'Brien, 2014), or to understand career self-management and career satisfaction (Jung \& Takeuchi, 2018). Because career success is commonly seen as a desirable state or object (Arthur et al., 2005; Gunz \& Heslin, 2005), we propose that COR offers a highly useful framework for understanding career success, including its process, predictors, conditions, and outcomes.

A first basic assumption of COR theory is that resources are critical in attaining valued aims, and that resources can exist at the personal and contextual levels. This implies that one theoretical explanation for between-person differences in career success is that people differ in the extent to which they can draw on personal and/or contextual resources to achieve their career success goals. These resources pertain to more volatile personal resources (e.g., knowledge, experience, awareness) as well as proximal environmental resources (e.g., supervisor support, organizational policies, employment type; Halbesleben et al., 2014). In addition, they also pertain to more structural personal key resources (e.g., self-esteem, optimism, or personality traits) and contextual macro resources (e.g., culture, labor market, or social welfare systems; Hobfoll, 2002; Ten Brummelhuis $\&$ Bakker, 2012). In addition to providing direct means for obtaining valued aims, these structural resources can foster or inhibit resource creation or usage (Hobfoll et al., 2018). Applied to career success, this suggests that personal key and contextual macro resources, such as stable traits, national culture, and the labor market, can have important effects on career success by facilitating or obstructing the use and development of other critical career resources.

An additional assumption of COR theory is that resources protect against resource loss (Hobfoll et al., 2018). The availability of resources thus enables people to better handle challenges and hurdles in career development, and to attain success ( $\mathrm{Ng} \&$ Feldman, 2014a, b). Especially given the current career context, which is characterized by increasing volatility and uncertainty (Sullivan \& Baruch, 2009; Wang \& Wanberg, 2017), being able to draw on resources that support coping with expected and unexpected challenges and traumas in career development is regarded as critical to attaining favorable career outcomes (Hall, 2002). Importantly, COR theory is explicitly dynamic and does not propose a static view of available resources. A core tenet of COR theory is that people actively strive to obtain, retain, foster, protect, and utilize resources that help them to achieve valued aims (Hobfoll et al., 2018). Hence, an additional theoretical explanation for the attainment of career success based on COR theory is that people develop resource management behaviors and attitudes to optimize the attainment of career success (e.g., political behavior, self-directed career attitude, career planning; Ferris, Witt, \& Hochwarter, 2001; Sullivan \& Baruch, 2009; Wayne, Liden, Kraimer, \& Graf, 1999).

Finally, COR theory proposes that resources can generate other resources, and that interactions between resources accumulate into outcomes over time (i.e., resource caravans, resource gain spirals, resource loss cycles; Hobfoll et al., 2018). Applied to the understanding of career 
success, this means that the accumulation and dynamics of resources over time, such as resource changes caused by voluntary or involuntary career transitions (Feldman \& Ng, 2007), or changes in resources over one's lifespan (Jung \& Takeuchi, 2018), play an important role in understanding the attainment of career success.

Dominant theoretical approaches to the study of (antecedents of) career success. The study of career success has been approached from a vast array of theoretical angles (e.g., Arthur et al., 2005; Feldman \& Ng, 2007; Gunz \& Heslin, 2005; Hall \& Chandler, 2005), indicating competing perspectives of which theoretical approaches dominate the field. Feldman and $\mathrm{Ng}$ (2007) — in their review of career mobility, embeddedness, and success - claimed that although researchers draw on a wide variety of theoretical approaches, research on career development has been dominated by a few paradigms: valence-instrumentality-expectancy models, the stress-coping paradigm, role theory, and network theory in particular. Wang and Wanberg (2017), by contrast, claimed that dominant theoretical approaches to the study of careers have been person-environment fit theories, lifespan career development theories, protean and boundaryless career models, and cognitive and social-cognitive theories. Reviews that have focused on specific aspects or antecedents of career success have either theoretically positioned themselves within the boundaryless career framework (Arthur et al., 2005), mobility and embeddedness (Feldman \& Ng, 2007), contest and sponsored mobility perspectives (Ng \& Feldman, 2005), COR theory (Ng \& Feldman, 2014a, 2014b), or broaden and build theory (Boehm \& Lyubomirsky, 2008). In addition to making claims about the theoretical approaches that have dominated research in the past, scholars have also identified a number of theoretical perspectives that they believe should receive more attention in future research. A common thread is a suggested focus on career self-management, within an assumed context of labor market volatility (e.g., Hall, 2002; Mainiero \& Sullivan, 2005; Sullivan \& Baruch, 2009). Sullivan and Baruch (2009), among others, identified protean, boundaryless, post-corporate, hybrid, and kaleidoscope career models as "the most fruitful opportunities for research directions in the coming decades" (p. 1544).

These competing perspectives are organized in our review framework based on the degree to which they focus on (a) personal resources (e.g., role theories, contest mobility perspective, human capital theory), (b) proximal environmental resources (e.g., network theory, sponsored mobility perspective), (c) resource management behaviors and attitudes (e.g., stress and coping paradigm, social-cognitive career theory, self-management), (d) personal key resources (e.g., trait theories), (e) contextual macro resources (e.g., national culture, labor market), or (f) resource accumulation and dynamics (e.g., career transition theories, person-environment fit theory).

Theoretical differentiation in explaining the attainment of OCS versus SCS. Although competing perspectives of the need for theoretical differentiation of the attainment of OCS and SCS exist (e.g., Arthur et al., 2005; Dries \& Verbruggen, 2012; Mayrhofer et al., 2016; Rodrigues \& Guest, 2010), several scholars have pointed out that empirical research should better account for the conceptual and theoretical differences between OCS and SCS (e.g., Arthur et al., 2005; Mayrhofer et al., 2016).

Human capital theory (Becker, 1962) is among the theories that seem better aligned with the operationalization of career success as OCS (Ng et al., 2005). This theory states that competencies 
acquired by individuals predict diverse life and career outcomes, including career success. Specifically, it proposes that differential individual investments in developing competencies (e.g., through education or experience) will be differentially rewarded by the labor market (e.g., through higher salaries, Baruch \& Lavi-Steiner, 2015; Ng et al., 2005). Similarly, tournament theory (Connelly, Tihanyi, Crook, \& Gangloff, 2014) and the contest mobility perspective (Ng et al., 2005) seem better suited to understanding OCS because they imply the external (e.g., social, organizational) awarding of career success to individuals based on their efforts, characteristics, or achievements, whereas SCS is an internal, subjective experience. In light of our resource management framework, these theoretical approaches seem to share the assumption that developing a range of personal resources (e.g., competencies, work achievements) is pivotal to attaining OCS. We thus expect (1) to find more studies with a theoretical approach that focuses on personal resources among studies that only examine OCS (as compared to studies examining only SCS).

Theoretical approaches that focus on personal fulfillment and career self-management, in contrast, not only highlight the (increasing) importance of SCS, but also appear better suited for explaining the attainment of SCS (e.g., Hall \& Chandler, 2005; Mainiero \& Sullivan, 2005; Sullivan $\&$ Baruch, 2009). The calling model of psychological success (Hall \& Chandler, 2005), the kaleidoscope career model (Mainiero \& Sullivan, 2005), and the protean career model (Hall, 2002), among others, all focus on internal processes that guide idiosyncratic, best-fit career decisions, with OCS taking the role of a possible, but unnecessary, by-product (Hall \& Chandler, 2005). Furthermore, past reviews and theory work specifically acknowledged the role of stable traits (e.g., Heslin et al., in press; $\mathrm{Ng}$ et al., 2005), stress experiences (e.g., $\mathrm{Ng} \&$ Feldman, 2014b), and cognitive mechanisms (e.g., attribution theory and social comparison theory, $\mathrm{Ng}$ et al., 2005) in explaining SCS. Against the backdrop that SCS is defined as a focal career actor's evaluation and experience of achieving personally meaningful career outcomes (Seibert, 2006), it seems reasonable that personality traits, stress experiences, and cognitive information processing are more proximal to the (internal) evaluation of SCS than to the (external) attainment of OCS.

Within our resource management framework, this implies that theoretical approaches that focus on resource management behaviors and attitudes (e.g., social-cognitive and cognitive processes, career self-management, stress and coping), and on personal key resources (e.g., stable traits) are key to understanding SCS. We thus expect (2) to find more studies with a theoretical approach focusing on resource management behaviors and attitudes, and on personal key resources, among studies that only examine SCS (as compared to studies examining only OCS).

Finally, there are some theoretical approaches that seem appropriate for understanding both OCS and SCS. The sponsored mobility perspective (Turner, 1960), for instance, describes how established senior members of an organization will often pay special attention to high-potential employees and provide sponsorship to them (i.e., special assignments, career support, and material resources), resulting in improved odds of career success. Sponsored employees are more likely to both achieve OCS - for instance, in the form of fast-track promotions - and to experience SCS because of their higher levels of psychosocial support and autonomy (Wu, Foo, \& Turban, 2008). Indeed, studies looking at the effects of mentoring and social capital found similar results for OCS and SCS (Eby, Allen, Evans, Ng, \& DuBois, 2008; Ng et al., 2005; Seibert, Kraimer, \& Liden, 
2001). Role and identity theories (e.g., Eagly \& Karau, 2002) seem suitable to explain both OCS and SCS, as well, because conforming to (stereotypic) role expectation signals career potential to career decision makers in organizations, leading to higher OCS (Kirchmeyer, 1998), whereas a clear sense of one's own roles and identity is related to SCS (Sullivan \& Baruch, 2009). Finally, mobility theories seem to be well-suited to study both OCS and SCS (Feldman \& Ng, 2007) because they allow for a differential explanation of different types of mobility on OCS versus SCS. For instance, voluntary organizational or occupational change usually results in a higher person-environment fit that goes along with higher levels of SCS. Organizational change can also be applied as a career strategy, with the goal to achieve higher levels of OCS, whereas occupation change is largely unrelated and can also be negatively related to increases in OCS (Feldman \& Ng, 2007).

In light of our resource management framework, this suggests that theoretical approaches that focus on proximal environmental resources (e.g., networks, social support, sponsored mobility), contextual macro resources (e.g., national culture, labor market), and resource accumulation and dynamics (e.g., career transitions, person-environment fit) are important for explaining the attainment of both OCS and SCS. We thus expect (3) that existing research on OCS and SCS has adopted these theoretical approaches in equal measure.

\section{A Resource Management Perspective on Outcomes of Career Success}

In addition to offering a range of theoretical insight that helps understand the emergence of career success, COR theory offers assumptions for building an organizing framework that includes potential outcomes of career success. In fact, indicators of career success, such as high salaries or high-status positions, can be seen as resources that are valuable in their own right, that are perceived as such by other people, and that help attain further goals (Hobfoll, 2002; Ten Brummelhuis \& Bakker, 2012). Career success in itself can thus be understood as a resource that helps to attain other valued internal or external states and objects. Some empirical research has indeed found effects of career success on outcomes, such as organizational/occupational embeddedness and reduced turnover intentions (Stumpf, 2014), organizational commitment (Gao-Urhahn et al., 2016), positive career related expectancies or beliefs, such as self-efficacy (Lent, Brown, \& Hackett, 1994; Spurk $\&$ Abele, 2014), and increased well-being (Abele et al., 2016; Judge \& Kammeyer-Mueller, 2012). In addition, resources can function as a signal to other people, and influence their emotions and behaviors (Hobfoll et al., 2018). It is thus highly likely that successful people are treated differently by their environment-i.e., by gaining social prestige and peer respect (Hall \& Chandler, 2005; Heilman, Wallen, Fuchs, \& Tamkins, 2004), or additional career opportunities and mentoring support (Singh, Ragins, \& Tharenou, 2009b). Furthermore, some theoretical models have assumed positive feedback loops between career success and other variables. Social-cognitive career theory (Lent et al., 1994), for instance, suggests that career self-efficacy can be both an antecedent and an outcome of success, implying reciprocal causality.

COR theory also provides assumptions that might explain potential negative outcomes of career success. COR theory proposes that people aim to protect their resources (Hobfoll et al., 2018), and that a failure to protect career success might result in significant distress (Duff \& Chan, 2014). Being successful might thus cause people to engage in actions aimed at sustaining their success. For example, career success might induce people to engage in (unethical) protective behaviors (e.g., 
mobbing) to maintain their position against threats (e.g., a rising star among their coworkers). Alternatively, success might induce people to work even harder to protect their career attainments, for example, in an attempt to avoid being laid-off or outflanked by a competitor (Keller, Spurk, Baumeler, \& Hirschi, 2016). In addition, instead of receiving positive reactions from the proximal environment, highly successful people might be treated with envy, and excluded from or stigmatized by social groups (Heilman et al., 2004).

Finally, the mere pursuit of career success can be accompanied by negative outcomes. One important principle of COR theory is that people must invest resources to gain or protect resources (Hobfoll et al., 2018). We can thus assume that in the pursuit or protection of career success, people will not only gain and maintain resources, but also invest resources (e.g., time, energy, money) that will subsequently no longer be available for pursuing other valued states or objects. As such, attaining and sustaining career success becomes a double-edged sword, where career success is accompanied by the depletion of valued other resources, leading to, for example, work-family conflict (Greenhaus \& Kossek, 2014; Ten Brummelhuis \& Bakker, 2012), exhaustion, or experienced failure in other life domains (Baruch \& Vardi, 2016; Korman et al., 1981).

From a resource management perspective, the outcomes of career success - and whether or not these are more likely to be positive or negative-will also depend on whether we conceptualize it as OCS or SCS. OCS is, by definition, visible to third parties, whereas SCS is not (Dries et al., 2009; Gunz \& Heslin, 2005). The former can therefore be expected to more strongly affect variables external to the individual, for example, career outcome attributions made by others in the social environment (Hall \& Chandler, 2005), or social support in the form of mentoring (Singh et al., 2009b). Moreover, OCS is likely to be associated with higher levels of interpersonal competition, heavy work investment, peer envy, and demands on the work-nonwork interface, all of which may result in resource depletion and undesirable outcomes (Greenhaus \& Kossek, 2014; Halbesleben et al., 2014; Korman et al., 1981). By contrast, we can expect SCS to have stronger effects on internal processes, such as increased work motivation, positive identity change, the development of a sense of calling, subjective well-being, and lower turnover intentions (Abele et al., 2016; Feldman \& Ng, 2007; Hall \& Chandler, 2005). From this perspective, it is thus more likely that OCS - as compared to SCS—will lead to negative, undesirable outcomes.

Based on past work that has included outcomes of career success (e.g., Abele et al., 2016; Boyce, Brown, \& Moore, 2010; Hall \& Chandler, 2005; Lent et al., 1994), and on the assumptions reported above, we expect (4) to find that empirical research, to date, has examined outcomes of career success related to (a) withdrawal (e.g., turnover intentions; Stumpf, 2014), (b) career attitudes (e.g., occupational self-efficacy; Spurk \& Abele, 2014), (c) well-being and health (e.g., life satisfaction or mortality; Judge \& Kammeyer-Mueller, 2012), and (d) reactions from the (work) environment (e.g., success/personal failure perceptions; Hall \& Chandler, 2005).

\section{Review Method}

With the aim of examining the competing perspectives identified in the literature as discussed above, and to provide an overview of research on outcomes of career success, we set out to review quantitative studies on antecedents and/or outcomes of career success that explicitly labeled at least one empirically measured variable as career success, irrespective of the indicators and measures 
used. In consideration of content validity, however, studies using operationalizations of career success that violated the construct were not included in the review. This decision was based on the observation made in previous reviews that career success seems to have become a catchall signifier (Feldman \& Ng, 2007). Although variables, such as educational level or organizational commitment, are occasionally treated as indicators of OCS and SCS, respectively (Feldman \& Ng, 2007), these variables are more commonly understood to be antecedents of career success rather than measures of the construct itself (e.g., Dries et al., 2009; Heslin, 2003; Ng et al., 2005; Ng \& Feldman, 2014a, Shockley et al., 2016). We focused on quantitative studies in particular because such studies most clearly identify antecedents and outcomes of career success-both theoretically and empirically. However, this selection decision should be considered when interpreting the findings of the review.

We searched Web of Science for the term career success within the search fields title, abstract, keywords, and extended keywords. We searched the total available time span in Web of Science (i.e., from 1900 until 2016). We restricted our search to journals in management and applied psychology. In addition to this main search, we searched some leading journals in both fields (e.g., Administrative Science Quarterly, Academy of Management Journal, Journal of Applied Psychology, Journal of Management), as well as the leading journals in the field of careers (e.g., Journal of Vocational Behavior, Journal of Career Assessment) for in press publications that did not come up through our Web of Science search across all journals. This search strategy resulted in a total of $k=592$ hits (585 from Web of Science and 7 in press articles). After an initial screening of these publications, 348 articles were excluded from the final article pool because they were (a) theoretical papers, qualitative papers, other review work, or did not analyze antecedents or outcomes of career success $(k=75)$; or (b) did not explicitly label any measured variable as (an indicator of) career success $(k=273)$. This resulted in a final $k$ of 244 publications (encompassing 266 individual studies because some articles reported findings from multiple studies, see Supplemental Material 1). Between the years 1973 and 1999, 37 (13.9\%) studies were published; between 2000 and 2009, 94 (35.3\%) studies were published; and between 2010 and 2016, 135 (50.8\%) studies were published, implying a general increase in career success research over the past few decades. Table 1 provides an overview of relevant characteristics of the career success studies included in our review.

\section{Taxonomy of Theoretical Approaches to the Study of (Antecedents of) Career Success}

We developed a taxonomy that allowed us to organize the theoretical approaches reported in the studies in our review into meaningful theoretical categories. Based on previous reviews of the career (success) literature (see theory section: Arthur et al., 2005; Boehm \& Lyubomirsky, 2008; Feldman \& Ng, 2007; Ng et al., 2005; Ng \& Feldman, 2014a; Ng \& Feldman, 2014b; Sullivan \& Baruch, 2009; Wang \& Wanberg, 2017), we expected the following categories to emerge: roles and identity, human capital, contest mobility, social support/sponsored mobility, agentic career management, stress and coping, stable traits, career transitions, person-environment fit, and lifespan development. The first and second author independently categorized articles into these predefined theoretical categories, and added new categories if needed. Only explicit mentioning of theoretical approaches was considered (see Supplemental Material 2 for a more detailed coding description). Inter-rater reliability was solid (kappa $=.73)$. In a next phase, their results were compared, and agreement on the final, best-fitting categorization and label for each identified theoretical approach 
category was reached through discussion. To decide whether a specific theoretical approach fit within a given category, we took into account the central assumptions of the approach. For example, the central assumption of social capital theory is that individuals in the social environment of a career actor provide different types of resources (e.g., information, psychosocial help, career support) that can contribute to that focal actor's career success (Seibert et al., 2001). Consequently, social capital theory was classified under the social support category (which was later renamed to social environment to tap the broader content of the final category). Across the 259 studies analyzing antecedents of career success, 559 theoretical approaches were classified into the taxonomy, which ultimately consisted of 14 categories - four categories were added to the ten listed above: work environment, national culture, hybrid theories, and single occurrences (see Table 2). In a final step, we sorted each category into superordinate categories in keeping with the review's resource management framework. Table 2 reports the final taxonomy, including definitions for each of the 14 categories, as well as frequencies of occurrence, organized according to whether studies measured OCS only, SCS only, or both OCS and SCS. A more detailed table where coded theoretical approaches are linked to all included articles can be seen in Supplemental Material 2.

\section{Taxonomy of Outcomes of Career Success}

Only 38 studies (14.3\%) examined outcomes of career success. In 13 of these studies, measures of career success were theoretically assumed as an outcome of another measure of career success - mostly SCS as an outcome of OCS. We therefore chose to focus our review on the 25 studies that included outcomes of career success that were not themselves measures of career success. We combined a theory-driven with a data-driven approach to classify outcomes into categories. Based on past research (discussed earlier), we took the following categories as a starting point: (a) withdrawal outcomes, (b) career attitude outcomes, (c) well-being and health outcomes, and (d) reactions from the (work) environment outcomes. A fifth category was added based on our review of the 25 relevant studies, which was (e) self-concept outcomes. Inter-rater reliability was perfect $($ kappa $=1)$. Table 3 reports the final taxonomy. Additionally, in the table, we list the theoretical approaches adopted by these studies to explain the relation between career success and its outcomes. We also indicate the number of studies that applied a time-lagged design or another type of design that approximates for causal inference (e.g., longitudinal designs applying change analysis or vignette experiments). We also included studies with a cross-sectional design in the table because they can also offer relevant theoretical insight for future research.

\section{Review Findings}

\section{Theoretical Approaches to the Study of (Antecedents of) Career Success}

To provide more clarity about the competing perspective about which theoretical approaches dominated past research on antecedents of career success, we display our findings of the reviewed frequency in Table 2 . As can be seen, we were able to link nearly all identified theoretical approaches across the studies in our review sample to our resource management framework (for instance, theories related to human capital, roles and identity, and competitive performance could all be linked to the notion of personal resources). Theoretical approaches encompassing multiple resources in a more balanced manner were labeled hybrid approaches; in addition, there were some single occurrences of theories that were found in only one empirical article (e.g., labor market seg mentation 
theory, which focuses on contextual macro resources). A first conclusion is that past research on career success seems to have drawn from an even wider and more heterogeneous range of theoretical approaches than assumed by previous reviews of the literature (e.g., Arthur et al., 2005; Feldman \& Ng, 2007; Sullivan \& Baruch, 2009; Wang \& Wanberg, 2017).

Dominant theoretical approaches. Theoretical approaches focusing on proximal environmental $(42.1 \%)$ and personal $(40.2 \%)$ resources were most prevalent in past research, followed by resource management behaviors and attitudes $(31.7 \%)$, and resource accumulation and dynamics $(20.5 \%)$. More specifically, theoretical approaches focusing on the social environment (34.0\%; e.g., social capital theory) and career agency (27.4\%; e.g., social-cognitive career theory) were most prevalent, followed by approaches focusing on human capital (21.2\%; e.g., human capital theory) and roles and identity (16.6\%; e.g., gender role theory). Personal key resources, contextual macro resources, and other approaches (hybrid and single occurrences) were relatively less prevalent (all $\leq 12.0 \%$ ). These results suggest that in spite of the heterogeneity of the theoretical approaches used, we can identify some dominant and therefore influential approaches in past research on antecedents of career success - i.e., theories focusing on the social environment, on career agency, on human capital, and on roles and identity.

Time trends in dominance. We also analyzed whether the relative dominance of theoretical approaches had shifted over time. Frequently used approaches in the current decade include career agency (i.e., 31.8\%), social environment (36.4\%), and person-environment interactions and human capital (both 16.7\%). Conversely, before the year 2000, the most cited theoretical approaches were human capital (40.0\%), roles and identity (34.3\%), and social and work environment (both $28.6 \%$ ). These findings imply a somewhat declining interest in human capital, roles and identity, and work environment, and an increasing interest in career agency as theoretical approaches for studying career success. Theoretical approaches focusing on the social environment, however, have remained equally prevalent. This suggests that empirical career success research has been responsive to conceptual trends (e.g., a stronger focus on career agency like self-management or protean careers; Sullivan \& Baruch, 2009), while consistently relying on a few established theoretical approaches (e.g., sponsored-mobility perspectives; $\mathrm{Ng}$ et al., 2005).

Dominance across studies: Summary and conclusion. Together, these findings provide insight into competing perspectives in the literature about the dominance of different theoretical approaches. On the one hand, there is partial overlap with assessments of dominant theoretical approaches made by past reviews (e.g., $\mathrm{Ng}$ et al., 2005; Feldman \& $\mathrm{Ng}$, 2007; Wang \& Wanberg, 2017). For example, valence-instrumentality-expectancy models (Ng \& Feldman, 2007), protean and boundaryless models, and social-cognitive approaches (Wang \& Wanberg, 2017) —all relating to resource management behaviors and attitudes (i.e., career agency) within our resource management framework-were identified as dominant theoretical approaches by past reviews, as well as by the current (more quantified) review. The same applies to network theory ( $\mathrm{Ng} \&$ Feldman, 2007) and sponsored mobility ( $\mathrm{Ng}$ et al., 2005) approaches — which both relate to proximal environmental resources. On the other hand, some theoretical approaches emerged from our systematic analysis of the literature as less dominant than would be expected, based on earlier review articles. For instance, although two recent meta-analyses of the field were framed within the stress 
and coping paradigm (Ng \& Feldman, 2014a, b), and although Wang and Wanberg (2017) identified lifespan career development theories as central to the study of career development, both approaches were only referred to in $5.0 \%$ and $5.4 \%$ of empirical studies on career success, respectively. Similarly, although Feldman and $\mathrm{Ng}$ adopted embeddedness and mobility as a framework for their 2007 review article, studies that explicitly cite career transition theories have been rare (3.5\%). Finally, the present review identified theoretical approaches that have not been mentioned by review articles before-mostly within the contextual macro resources category-pointing toward potentially unexplored areas in existing research (i.e., national culture [3.1\%], and single occurrences, such as labor market segmentation theory).

Comparison of theoretical approaches/antecedent classes within single studies. In addition to examining the heterogeneity and dominance of theoretical approaches across articles, we took a closer look at studies that explicitly compared multiple theoretical approaches or related antecedent classes because such studies might be specifically indicative of the usefulness of some approaches. We identified only 23 studies (8.6\%) that met this criterion (see Supplemental Material 3 for details). Notably, none of the studies included a-priori hypotheses aimed at explicitly comparing the relative predictive power of these theoretical approaches. Rather, the common approach was to assume that the different theoretical approaches, taken together, provided useful insights; however, the relative usefulness was tested in an explorative manner. Moreover, some studies did not statistically evaluate the relative merit or predictive value of different theoretical explanations, but simply showed that several variables representing different theoretical approaches were related to OCS and/or SCS. Another important observation was that the same theoretical approaches, across the 23 studies, were measured using very different variables (e.g., human capital was, for instance, operationalized as perceived usefulness of education, English language ability, leave of absence, international experience, or extraversion). Conversely, across the 23 studies, the same measures were linked to different theoretical approaches (e.g., personality traits were claimed to represent human capital in some studies, and individual differences in others; Supplemental Material 3).

Some studies produced some interesting comparative insights, such as showing that human capital accounted for 39\% of total explained variance in OCS, sociodemographic attributes for 34\%, individual differences for $14 \%$, and social capital for $13 \%$, in a sample of African-American males (Johnson \& Eby, 2011); or that personal capital (36\%), business strategies (26\%), and social capital $(21 \%)$ explained the largest proportion of variance in SCS in a sample of freelance workers, whereas human capital, market factors, and motivation capital were much less predictive (Van den Born \& Witteloostuijn, 2013). In sum, however, the current state of the literature precludes drawing firm conclusions as to which theoretical approaches better explain career success - an issue that we will address in more depth in the section on future research directions.

\section{Theoretical Differentiation in Explaining the Attainment of OCS versus SCS}

Dominance of theoretical approaches for OCS versus SCS. As concerns the competing perspectives found in the literature about the need for theoretical differentiation in the study of antecedents of OCS versus SCS, our review yielded mixed results (see Table 2). On the one hand, the proportion of studies examining OCS and SCS together did not seem to differ depending on which theoretical approach they used-and overall, most studies included both types of career 
success (see Table 2). Moreover, there was no theoretical approach that was used exclusively to study OCS or SCS, which supports the perspective that the prediction of OCS and SCS might not necessarily require different theoretical assumptions. On the other hand, when comparing studies that analyzed OCS only versus SCS only, some theoretical approaches were more frequently used to examine one type of success over the other, which supports the perspective that theoretical differentiation has, in fact, been applied, and pointing toward the need to do so. These results are specifically useful in understanding different theoretical explanations of (the antecedents of) OCS versus SCS.

Dominant approaches in studying antecedents of OCS. As expected, among studies that cited theoretical approaches focusing on personal resources, 40.4\% looked at OCS only, whereas $16.3 \%$ looked at SCS only. This pattern was most typical for studies relying on human capital approaches (38.1\% OCS only vs. $7.3 \%$ SCS only) and (competitive) performance approaches (41.4\% OCS only vs. $13.8 \%$ SCS only), whereas studies adopting roles and identity approaches did not show such a clear difference (37.2\% OCS only vs. $27.9 \%$ SCS only). This finding partially supports our expectation that theoretical approaches focusing on personal resources-especially human capital and (competitive) performance approaches - might be better suited to explaining OCS rather than SCS, and were therefore primarily selected in studies that analyzed OCS only. These findings are in line with the meta-analysis by $\mathrm{Ng}$ et al. (2005), which stated that human capital theory is particularly fitting for predicting OCS. More specifically, theoretical approaches that focus on an individual's work-related knowledge, skills, and competences (e.g., general mental ability, allocation of energy model), and the performance level/rank of an individual (e.g., tournament theory, contest mobility perspective) seem to be most representative of the theoretical basis for explaining the attainment of OCS.

Dominant approaches in studying antecedents of SCS. Studies that cited theoretical approaches focusing on resource management behaviors and attitudes (12.2\% OCS only vs. $36.6 \%$ SCS only), as well as personal key resources (12.9\% OCS only vs. $25.8 \%$ SCS only), more frequently looked at SCS only than at OCS only. This pattern was the same among all theoretical approaches categorized under resource management behaviors and attitudes (i.e., career agency approach: $11.3 \%$ OCS only vs. $36.6 \%$ SCS only; stress and coping: $15.4 \%$ OCS only vs. $38.4 \%$ SCS only). These findings support our assumption that theories that focus on resource management behaviors and attitudes, as well as personal key resources, were predominantly used-and are thus potentially better suited - to explaining SCS rather than OCS. These findings are in line with views that assume that stable individual differences and new career concepts, such as boundaryless and protean career orientation, are key in understanding the attainment of SCS (Arthur et al., 2005; Hall \& Chandler, 2005; Heslin et al., in press; $\mathrm{Ng}$ et al., 2005). More specifically, theoretical approaches that focus on an individual's work attitudes, career management, proactive behaviors (e.g., protean career theory, social cognitive career theory), and stable personality characteristics (e.g., Big Five model, RIASEC model), seem to be most representative of the theoretical basis for explaining the attainment of SCS.

Dominant approaches in studying antecedents of both OCS and SCS. As expected, studies that cited theoretical approaches focusing on proximal environmental resources $33.0 \%$ OCS only 
vs. $24.8 \%$ SCS only) did not exhibit a clear relation with type of career success studied — this applied both to approaches focusing on the social and the work environment. Counter to our expectations, however, the prevalence of studies that cited approaches focusing on resource accumulation and dynamics (32.1\% OCS only vs. 17.0\% SCS only) differed between studies that looked at OCS versus SCS only. This was mainly due to person-environment interaction approaches, which were slightly more often used in studies on OCS only (34.3\%) than on SCS only (20.0\%). These findings partially support our assumption that theories focusing on resource accumulation and dynamics are equally prevalent - and thus potentially equally well-suited - to study OCS and SCS. More specifically, theoretical approaches focusing on proximal environmental (e.g., social capital theory, signaling theory, internal labor market theory), and contextual macro resources (e.g., Schwartz's theory of basic human values, labor market segmentation theory), as well as on life span (e.g., ageing theories, theories on career stages) and career transition issues (e.g., path dependency approaches, international career logics typology) seem to be most representative of the theoretical basis for explaining the attainment of both OCS and SCS.

To conclude, although the reviewed results on dominance are an indicator that past research has started to transfer OCS/SCS conceptualization issues into research on antecedents of career success, future research still has to make important decisions regarding this line of research.

Differential hypotheses for OCS versus SCS within single studies. As the same theoretical approach can also be used to make differential predictions for OCS and SCS-for example, when the same theory predicts a positive effect on OCS but a negative or null effect on SCS - we examined how many of the 120 studies that measured both types of success explicitly stated such differential hypotheses. We found this to be the case in only 22 (18.3\%) of the studies (Table 1) - of which 18 were published after 2004. A recent study of older workers (Hennekam, 2016), for instance, hypothesized and found that integrity positively predicted SCS, but not OCS, as the latter type of success is more influenced by factors directly visible to organizations. Another study (Wu et al., 2008) drew on social network theory to hypothesize a positive relation between career assistance and both OCS and SCS, but also between psychosocial assistance and SCS only. The study did not find support for the proposed unique effect of psychosocial assistance on SCS, however. By contrast, using a contest mobility perspective, a study by Wayne et al. (1999) hypothesized and found that a desire for upward mobility was positively related to OCS, but negatively to SCS, possibly because individuals may have unrealistic expectations concerning the amount of time and effort needed to achieve such goals, and because the flattening of structures in many organizations provide fewer opportunities for upward mobility. Finally, Van den Born and Witteloostuijn (2013) found, as expected - based on the applied intelligent career framework - that flexibility and work-life balance motivations were negatively related to OCS, but positively to SCS. In summary, these studiesalthough quite rare to date-illustrate the value of developing differential hypotheses for antecedents of OCS and SCS, and lead to the important conclusion that a differential conceptual and empirical understanding of antecedents of both forms of career success does not necessarily require the use of different theories. We will come back to this issue when explaining avenues for future research.

\section{Outcomes of OCS versus SCS}


In spite of the relatively low prevalence of studies examining outcomes of career success, an increasing trend has been observed since 2008 (i.e., 2 studies before 2008, compared to 23 from 2008 onwards). The prevalence of studies examining outcomes of OCS versus SCS was largely balanced, with $32 \%$ of studies focusing on OCS only, $31 \%$ on SCS only, and $37 \%$ on both types of success. Most of the 25 studies (72\%) looking into outcomes of career success also studied antecedents of career success, and 44\% applied a time-lagged design-implying that reverse causality cannot be fully excluded in over half (56\%) of these 25 studies. Again, especially considering the emerging nature of this research field, we identified numerous and diverse theoretical approaches explaining the relationship of OCS and SCS with their outcomes (see Table $3)$.

Five types of outcomes were identified, four of which were expected a priori based on previous conceptual and empirical work within career success research (e.g. Abele at al., 2016; Hall \& Chandler, 2005; Korman et al., 1981; Stumpf, 2014): withdrawal (40.0\% of studies), career attitudes $(36.0 \%)$, well-being and health $(24.0 \%)$, and reactions from the (work) environment $(16.0 \%)$. Self-concept outcomes $(8.0 \%)$ were added as an additional category. Overall, these findings suggest that research on career success has recently started to subscribe to the view that the attainment of career success is meaningfully related to other work and life outcomes. Although some outcomes of career success have not yet been analyzed extensively (e.g., reactions from the work environment or self-concept outcomes), it is an interesting observation that existing research has already looked at a range of possible outcomes. Our finding that withdrawal and career attitude outcomes were most studied was perhaps not surprising because these are most directly linked to organizational career management (Feldman \& Ng, 2007), and our search strategy focused on research in the fields of management and applied psychology. In what follows, we will review research on the different outcomes of career success, focusing specifically on studies that approximate for implications of causal inference.

Withdrawal outcomes. Withdrawal was equally often studied as an outcome of OCS and SCS. Two studies allowed for relatively strong causal conclusions. A first study (Stumpf, 2014) found that both OCS and SCS previously explained career mobility (i.e., changes in job, employer, and occupation) 12 months later. Specifically, individuals who had received more promotions and rated themselves higher in terms of SCS demonstrated less career mobility. Effects of salary became non-significant when SCS was entered into the prediction model. Another study (Pachulicz, Schmitt, \& Kuljanin, 2008) analyzed a sample of emergency physicians and found that both OCS (i.e., salary change) and SCS negatively predicted actual retirement, as well as intentions to leave medicine and emergency medicine at a later time. Taken together, these studies have suggested that both OCS and SCS affect withdrawal, but that SCS is a more proximal predictor-providing partial support for the assumption that SCS is more strongly related to outcomes related to internal processes (e.g., turnover intentions and decisions). Whether or not withdrawal is a positive or a negative outcome of career success - and consequently, is associated with resource gain or loss - is a matter of perspective, however. Although some authors have argued that regular career transitions are the key to happy and sustainable careers (Hall \& Chandler, 2005), others have focused on the costs of such transitions (Rodrigues \& Guest, 2010). 
Career attitude outcomes. Studies that looked at career attitude outcomes more often studied SCS rather than OCS. This observation is in line with theoretical assumptions about the nature of OCS and SCS - the latter being more associated with internal psychological processes (Shockley et al., 2016; Spurk \& Abele, 2014). OCS was analyzed as a predictor of career attitudes as well, however. For example, the study by Gao-Urhahn et al. (2016) explained (and found) positive longitudinal effects of salary change on organizational commitment change, and explained this finding using the reflection theory of compensation and social identity theory. Spurk and Abele (2014) relied on social-cognitive career theory to show that OCS positively affected changes in occupational self-efficacy expectations over time, mediated by more proximal SCS evaluations. Finally, Praskova, Hood, and Creed (2014)_building on the calling model of psychological success - found weak support for effects of SCS on career calling. Together, these findings have indicated that career success can change career attitudes in a positive manner, which supports the assumption that career success is a resource in and of itself that, in turn, affects resource management behaviors and attitudes.

Well-being and health outcomes. Although no study has looked at effects of career success on subsequent changes in well-being or health, two studies did apply a time lag between career success and such outcomes. One study (Judge \& Kammeyer-Mueller, 2012) found that individuals working in prestigious occupations — an indicator of OCS — between 1940 and 1960 showed higher levels of life satisfaction (up to 32 years later) and lower mortality (up to 42 years later). Income showed no effects on mortality. Similarly, another study (Judge, Ilies, \& Dimotakis, 2010) showed that individuals who worked in prestigious occupations had better objective and subjective health, as well as higher economic and subjective well-being, 3 to 9 years later. In sum, these findings provide support for the resource gain assumption that OCS constitutes an important resource for building further personal resources, in this case health, and well-being outcomes. Although the same might apply to SCS, to date, this link has not been investigated longitudinally within the fields of management and applied psychology.

Reactions from the (work) environment outcomes. Studies that looked into reactions from the (work) environment modeled them as outcomes of OCS only, in line with theoretical assumptions about the differential nature of OCS and SCS. Generally, these studies assumed that past and/or current OCS signals valuable information to the social environment (e.g., Singh et al., 2009b; Westman \& Etzion, 1990) that, for instance, increases the chances of receiving mentoring (Singh et al., 2009b). Stumpf and Tymon (2012) found positive effects of past promotions and salary changes on managerial assessments of a focal career actor's human capital value - meaning that the focal career actor was perceived as more competent in terms of human capital by his or her supervisor because of his or her past, visible OCS. Although this study was cross-sectional, otherreport measures collected from supervisors about the human capital of their subordinates provided some support for the expected direction of the effect. In addition to identifying positive effects of career success on reactions from the (work) environment, negative effects were also found. For instance, career success was associated with personal failure-attributed to a focus on the work domain and long working hours - as shown in an experimental vignette study (Westman \& Etzion, 1990). A more recent vignette study supported these findings by showing that objectively successful 
women were judged as less likable and more interpersonally hostile than men, especially in maledominated occupations (Heilman et al., 2004). These findings indicate that career success can be a double-edged sword, especially when considering the focal career actor's environment, meaning that OCS can lead both to proximal environmental resource gain or loss.

Self-concept outcomes. Finally-and quite surprisingly-self-concept outcomes, to date, have only been studied as outcomes of OCS, although they can be conceptually linked to SCS at least equally convincingly. Using functional role theory, a study by Kammeyer-Mueller, Judge, and Piccolo (2008) argued that self-regard reflects the degree to which a person lives up to the norms and expectations of his or her culture (for instance, in reference to occupational prestige). Selfconsistency theory, moreover, suggests that individuals will seek out clear indications of their occupational success (i.e., high income). Hence, those who have high levels of income will perceive income as an important indication of their self-worth. The study did not support these assumptions, however-perhaps because it did not account for SCS. Another study with a cross-sectional design, using retrospective career success evaluations and similar hypotheses to the Kammeyer-Mueller et al. (2008) study, found effects of OCS - measured as the number of promotions - on core selfevaluations (Stumpf \& Tymon, 2012). The cross-sectional nature of these results, however, limits causal interpretation. In sum, research on self-concept changes in response to career success has not yet been developed enough to infer clear implications about whether, how, and which type of career success might affect which aspects of the self-concept.

Summary and conclusion. Regarding the initial observation that career success research might be ripe for investigating more outcomes, our review showed that the last years were responsive to theoretical models that made such assumptions (Hall \& Chandler, 2005; Lent et al., 1994). In sum, we conclude that some of the antecedents that have been reviewed as predictors of career success in former work (e.g., Boehm \& Lyubomirsky, 2008; Feldman \& Ng, 2007; Ng et al., 2005; Ng \& Feldman, 2014a; Ng \& Feldman, 2014b) can also be modeled as outcomes of career success, implying reciprocal relations over time-i.e., career transitions and withdrawal, career agency and career attitudes, stress and coping, well-being, or work environment factors and social reactions. However, as can be seen in Table 1, relatively few (five studies, 1.9\%) have, in fact, tested reciprocal relations between career success and another outcome (Gao-Urhahn et al., 2016; Kammeyer-Mueller et al., 2008; Praskova, Hood, \& Creed, 2014; Spurk \& Abele, 2014; Stumpf, 2014), which demonstrates the need for further research in this area.

\section{Future Research Directions}

We derive several directions for future research on career success from the theoretical assumptions and empirical findings discussed in this systematic review. These future research directions acknowledge the need for a better understanding of both the antecedents and outcomes of career success, taking into account the conceptually different nature of OCS and SCS. Additionally, we formulate suggestions for dealing with potential dynamics and causality issues in the relationships between career success, its diverse antecedents, and its different outcomes.

\section{Making Sense of the Theoretical Heterogeneity in Career Success Research}

As our findings show, although the field of antecedents and outcomes of career success is characterized by a large theoretical heterogeneity, there also seems to be some convergence in terms 
of the theoretical approaches that are most often used to explain the attainment of career success (i.e., theories focused on the social environment, career agency, human capital, and roles and identity). Although theoretical heterogeneity can be beneficial to a field in terms of comprehensiveness, it also hampers accumulation of knowledge across studies, and leads to less clarity in terms of what are the most promising or urgent future research directions (Lee, Felps, \& Baruch, 2014). We propose that the present review - and especially Table 2 and 3-can help researchers navigate these heterogeneities and make more deliberate decisions about theoretical approaches and related antecedent and outcome variables, such that future career success research aligns more consistently and deliberately with previous work.

Specifically, first of all, although we identified a sizeable diversity in theoretical approaches, and although meta-analyses have reported effect sizes for different types of career success antecedents ( $\mathrm{Ng}$ et al., 2005; $\mathrm{Ng} \&$ Feldman, 2014a, b), the core question of which theoretical explanations are most promising in terms of predicting and understanding career success was not systematically and consistently answered (see also Supplemental Material 3). Therefore, future research would do well to more explicitly dissect the theoretical assumptions underlying the theoretical approaches they use (see Table 2 and 3), not only with the aim of identifying the most logical variables to operationalize them, but also to be able to identify competing assumptions on the relative importance that can subsequently be contrasted and tested. Statistical techniques, such as hierarchical regression analysis with incremental validity testing (Singh, Ragins, \& Tharenou, 2009a), dominance analysis (Tonidandel, LeBreton, \& Johnson, 2009; Van den Born \& Witteloostuijn, 2013), or direct model comparisons within structural equation modeling (e.g., Judge, Kammeyer-Mueller, \& Bretz, 2004), can thereby help refine our understanding of the relative predictive power of different explanations, and their related antecedents and outcomes of career success - and consequently allow for more focused theoretical and practical implications.

Second, our review showed that two studies focusing on the same antecedents (e.g., organizational turnover) can adopt different theoretical explanations (e.g., human capital versus career transition approaches), or that two studies with the same theoretical explanation (e.g., human capital approach) can focus on very different antecedents (e.g., age versus extraversion, see Supplemental Material 3). Hence, future studies contesting different theoretical explanations should develop clear and concise operationalization standards of antecedent (and outcome) variables within the compared theoretical approaches to the study of career success.

\section{Accounting for the Theoretical Differentiation of Correlates of OCS and SCS}

Our review findings suggest that existing empirical research has already acknowledged that OCS and SCS are distinct, but related, constructs that are related both to overlapping and different sets of antecedents and outcomes, and can be understood using either a single theoretical approach or a different approach for each set of relationships. That said, future research could adopt multiple strategies to further account for the OCS versus SCS distinction. To start with, based on our findings, future research on antecedents of career success should account for theoretical approaches that might be better suited to explain OCS (e.g., personal resources: human capital and competitive performance), to explain SCS (e.g., resource management behaviors and attitudes: career agency, or 
personal key resources: stable traits), or to explain both types of success (e.g., proximal environmental resources: social and work environment) when conceptualizing studies.

Although in some cases, OCS and SCS can be expected to be positively related (Dries \& Verbruggen, 2012; Hall \& Chandler, 2005; Rodrigues \& Guest, 2010), future research should more deliberately and systematically examine the antecedents and outcomes of OCS versus SCS — and under which conditions they can be expected to more strongly versus more weakly coincide. One study, for instance, showed that OCS and SCS are not related within the public sector, but more strongly related within the private industry, especially for entrepreneurs (Abele, Spurk, \& Volmer, 2011). Such findings suggest that the macro context, for instance, might define conditions for when to separate theoretical explanations of the attainment or consequences of OCS versus SCS.

Related to this, another avenue for future research is to design and run more studies that explicitly state differential hypotheses for OCS and SCS. This approach represents the most direct test of the idea that different theoretical assumptions apply to OCS and SCS. Future studies, then, should clearly separate their theoretical rationale for expected effects on OCS versus SCS, and/or include different antecedent (and potentially outcome) variables for both. Although 35.3\% of the studies reviewed reported moderation effects (Table 1), only two studies that tested differential hypotheses related to OCS versus SCS included moderators. These moderators, however, were not directly linked to the differential hypotheses. One study, for instance, assumed, but could not show that mastery goals are more strongly related to SCS than are performance goals, and that performance goals are more strongly related to OCS than are mastery goals (Van Dierendonck \& Van der Gaast, 2013). Future research, for example, could test under which work environmental conditions (e.g., competitive climate; Fletcher, Major, \& Davis, 2008) mastery and performance goals indeed positively relate to OCS versus SCS.

Another avenue for future research is to look into differential mediation mechanisms for

predicting OCS versus SCS, based on the same antecedents. Converse, Pathak, DePaul-Haddock, Gotlib, and Merbedone (2012), for instance, showed that self-control and proactive personality positively affected salary and occupational prestige through educational attainment, whereas the effect of self-control on career satisfaction was explained by achievement opportunities. Over time, the accumulated insights from such research endeavors could be translated into custom-fit recommendations for achieving and dealing with OCS and SCS in practice, through career counseling or human resource management.

\section{New and Alternative Theoretical Approaches to the Study of Career Success}

In addition to refining our understanding of the more established theoretical approaches to the study of career success - that is, by more explicitly examining the theoretical assumptions underlying different approaches, by making more consistent and deliberate choices in terms of antecedent and outcome variables, and by identifying differential moderating and mediating mechanisms to OCS and SCS, as discussed above-future research might also do well to consider currently underexplored, but potentially interesting new or alternative approaches. Specifically, regarding the prediction of career success, approaches that focus on resource management behaviors and attitudes (i.e., stress and coping), resource accumulation and dynamics (i.e., career transitions, 
lifespan), and contextual macro resources (i.e., national culture, labor market) need more attention in future research (e.g., Ng \& Feldman, 2014a; Wang \& Wanberg, 2017).

First, as for stress and coping approaches (e.g., Armstrong-Stassen \& Ursel, 2009), future research might look into which career success-related stressors or career shocks individuals have to cope with in order to be successful in today's work environment (e.g., Seibert et al., 2013). Theoretical approaches that focus on stress and coping, and that include taxonomies of possible stressors, such as transactional stress models (Folkman, Lazarus, Gruen, \& DeLongis, 1986) or conservation of resource theory (Hobfoll et al., 2018), would be best suited to study this type of research question. Such studies would answer the important question of which stressors present a threat to career success, how individuals react to career stressors, and whether stress is more strongly related to OCS or SCS.

Second, future research could focus more on theoretical approaches related to resource accumulation and dynamics. Although the concept of career mobility is central to the conceptual/theoretical literature on career success (Feldman \& $\mathrm{Ng}, 2007$ ), surprisingly few empirical studies have adopted theoretical approaches focusing on career transitions as the key mechanism to explaining career success. Although many studies reference career transitions at the variable level, they tend to adopt human capital gains caused by the transitions as one major theoretical explanation (Feldman $\& \mathrm{Ng}$, 2007). We propose that focusing more explicitly on career transition frameworks (e.g., Andresen \& Biemann, 2013) will be instrumental for better understanding the attainment of career success from a mobility perspective. Verbruggen, Van Emmerik, Van Gils, Meng, and de Grip (2015), for instance, developed a path-dependency perspective on career success to explain early-career effects of underemployment. Future research could adopt a similar approach to explain which combinations of early, mid, and late career transitions go along with what kinds of resource accumulation and converge into career success.

Moreover, as a result of the ageing workforce (Zacher, 2015b) and the ever-expanding time horizon of individual careers (Lee et al., 2014), lifespan approaches should become an important avenue for future research. On the one hand, lifespan approaches can help understand how different resources accumulate and transfer across life and career stages. For instance, some studies explained career success by accumulated advantages from early life and career experiences (Judge \& Hurst, 2008). Future research might test such long-term resource accumulation dynamics in more detail. On the other hand, it seems plausible that in late careers, different antecedents for career success might become relevant because of career plateauing among mid to older age groups (Smith-Ruig, 2009). A study by Van der Heijden, De Lange, Demerouti, and Van der Heijde (2009) on employability and age showed, for instance, that supervisor-rated employability was positively related to promotions for employees under 40, but negatively for employees over 40. Moreover, organizational career management affected career satisfaction differently within middle-aged employees compared to younger employees (Jung \& Takeuchi, 2018).

Third, there seems to be a lack of understanding of career success from a contextual macro resource perspective. Past research has acknowledged that the meaning of career success can differ between cultural/global regions (Mayrhofer et al., 2016) and occupational sectors (Spurk, Abele, \& Volmer, 2015). It did not, however, clearly distinguish between direct, indirect, or moderating 
effects of national culture or labor market factors on career success. Future research might look into developing testable assumptions from such macro-theoretical approaches to career success. A study by Holtschlag, Morales, Masuda, and Maydeu-Olivares (2013), for instance, showed that the relationship between individual (cultural) values and OCS varied considerably between 29 countries; similarly, Kats, Van Emmerik, Blenkinsopp, and Khapova (2010) suggested that HR practices can be expected to mediate cultural effects on career success.

\section{Positive versus 'Dark Side' Outcomes of Career Success}

One of the most promising directions for future research identified by this review is the need for more research on the potential outcomes of career success. Although there is some emerging research along these lines, more research is needed to determine how OCS and SCS affect the fundamental ways in which people think, feel, and behave. First, future research should further look into the effects of OCS and SCS on well-being and health. Surprisingly, the few studies that examined such outcomes have not offered much theoretical assumptions of why such effects would occur (see Table 3). Moreover, existing studies mainly assumed positive effects of career success on well-being and health. Based on our resource management framework, however, we would argue that, due to resource drain, role overload, time pressure, or unrealistically high performance expectations, negative effects of OCS are possible (Clark, Michel, Zhdanova, Pui, \& Baltes, 2016; Connelly et al., 2014; Korman et al., 1981). Therefore, future research might look into the boundary conditions under which effects of OCS on health and well-being are positive or negative (e.g., considering maladaptive or adaptive personal strategies how to deal with OCS).

Second, more attention should be paid on how the private and work environment of individuals is affected by, and reacts to, OCS and SCS. Especially OCS can be expected to signal power, influence, vitality, and available resources, but potentially also personal failure, high stress levels, and work-to-nonwork conflicts (Hall \& Chandler, 2005; Korman et al., 1981). Depending on how signals are perceived and evaluated by the environment, fundamentally different positive or negative reactions from the environment might follow (Connelly, Certo, Ireland, \& Reutzel, 2011). Future research could examine under which specific boundary conditions which type of career success leads to more positive (e.g., getting a mentor, Singh et al., 2009b) or more negative (e.g., perceptions of personal failure, Westman \& Etzion, 1990) reactions from the environment.

Third, only a few studies have looked at self-concept changes (i.e., core self-evaluations or self-esteem) induced by career success. A study by Sutin, Costa, Miech, and Eaton (2009) in the field of personality psychology found that OCS, but not SCS, predicted a change in neuroticism and agreeableness, but not the other Big Five traits. This implies that even traits assumed to be relatively stable might be changed by career success. To conceptually align self-concept outcomes to career success, future research might look at self-concept and personality characteristics that are more domain-specific and should hence be more directly reinforced by career success, such as trait competitiveness (Fletcher et al., 2008) or ambition (Judge \& Kammeyer-Mueller, 2012)—and whether OCS or SCS plays a larger part in such processes.

Finally, future research may want to expand its focus to other types of outcomes which have not yet been addressed in existing research. For example, based on the resource management framework in this review, we can assume that people might strive to protect their career success 
through a variety of means (e.g., increased work investment, unethical behavior, helping behaviors). Considering that one qualitative study recently reported that failure to protect career success might even result in suicide (Duff \& Chan, 2014), if and how people (successfully or unsuccessfully) invest in defensive or offensive career success protection efforts might be a particularly high-impact avenue for future research.

\section{Antecedent-Career Success-Outcome Dynamics and Causality Issues}

Although up until this point we have mostly listed separate directions for future research on antecedents and outcomes of career success, it is clear from our review framework that we see these aspects of career as inherently interrelated. In fact, we propose that future research should focus on developing dynamic and reciprocal frameworks of career success that include both antecedents and outcomes. As reciprocal relationships between career success and its antecedents and outcomes are theoretically highly plausible, future research should seek to disentangle the directionalities of these relationships. Moreover, specific outcomes might feed back into specific antecedents, resulting in self-reinforcing resource cycles over time (Hall \& Chandler, 2005; Hobfoll et al., 2018; Spurk \& Abele, 2014). Testing causal and reciprocal effects demands an empirical approach that is suited for causal inference. First, in addition to leaving a time lag between the measurement of career success and its antecedents and outcomes, future studies would do well to measure each of these variables at several points in time. Change analysis, such as cross-lagged panel models, latent growth curve models, or latent change models (e.g., Liu, Mo, Song, \& Wang, 2016) can then be applied to disentangle whether the relationships between career success indicators and related variables are unidirectional, reciprocal, or manifest in the form of parallel change processes (or yet other types of dynamics) over time.

Second, only a few existing studies have analyzed within-subject and/or short-term changes in career success and its correlates over time (e.g., Abele \& Spurk, 2009; Gao-Urhahn et al., 2016; Judge et al., 2010; Zacher, 2015). Within-subject changes in OCS and SCS - and their correlatesmight behave very differently and require different theoretical lenses and analyses compared to between-subject changes (Gao-Urhahn et al., 2016; Heslin et al., in press; Liu et al., 2016). Whereas indicators of OCS are assumed to fluctuate less rapidly, there is some evidence suggesting that SCS can fluctuate even at the daily level. In a recent study, 37\% of the variance in career satisfaction was due to daily within-person variance, and was better explained by within-person compared to between-person career adaptability (Zacher, 2015a). More such diary studies would also generate knowledge about short-term antecedents or outcomes of career success. By doing so, within-person and/or short-term change studies would be a complementary extension of mostly between- and/or long-term career success dynamics.

\section{Conclusion}

Against the backdrop of an organizing resource management framework, this review investigated two competing perspectives on the dominance, necessity, and usefulness of applying different theoretical approaches to explain the attainment of OCS versus SCS. Moreover, we complemented the view of career success as ultimate outcome of careers research and developed a taxonomy of potential outcomes of career success itself. We hope that the review findings and future research directions will result in a theoretically structured and comparative study of integrative 
antecedent-career success-outcome models that acknowledges the OCS/SCS distinction, and enrich theory in this research field. 


\section{References}

Abele, A. E., Hagmaier, T., \& Spurk, D. 2016. Does career success make you happy? The mediating role of multiple subjective success evaluations. Journal of Happiness Studies, 17: 1615-1633.

Abele, A. E., \& Spurk, D. 2009. How do objective and subjective career success interrelate over time? Journal of Occupational and Organizational Psychology, 82: 803-824.

Abele, A. E., Spurk, D., \& Volmer, J. 2011. The construct of career success: Measurement issues and an empirical example. Journal for Labour Market Research, 43: 196-306.

Andresen, M., \& Biemann, T. 2013. A taxonomy of internationally mobile managers. The International Journal of Human Resource Management, 24: 533-557.

Armstrong-Stassen, M., \& Ursel, N. D. 2009. Perceived organizational support, career satisfaction, and the retention of older workers. Journal of Occupational and Organizational Psychology, 82: 201-220.

Arthur, M. B., Khapova, S. N., \& Wilderom, C. P. M. 2005. Career success in a boundaryless career world. Journal of Organizational Behavior, 26: 177-202.

Baruch, Y., \& Lavi-Steiner, O. 2015. The career impact of management education from an average-ranked university: Human capital perspective. Career Development International, 20: 218-237.

Baruch, Y., \& Vardi, Y. 2016. A fresh look at the dark side of contemporary careers: Toward a realistic discourse. British Journal of Management, 27: 355-372.

Becker, G. S. 1962. Investment in human capital: A theoretical analysis. Journal of political economy, 70: 9-49.

Boehm, J. K., \& Lyubomirsky, S. 2008. Does happiness promote career success? Journal of Career Assessment, 16: 101-116.

Boyce, C. J., Brown, G. D., \& Moore, S. C. 2010. Money and happiness: Rank of income, not income, affects life satisfaction. Psychological science, 21: 471-475.

Bozionelos, N. 2004. The relationship between disposition and career success: A British study. Journal of Occupational and Organizational Psychology, 77: 403-420.

Clark, M. A., Michel, J. S., Zhdanova, L., Pui, S. Y., \& Baltes, B. B. 2016. All work and no play? A meta-analytic examination of the correlates and outcomes of workaholism. Journal of Management, 42: 1836-1873.

Connelly, B. L., Certo, S. T., Ireland, R. D., \& Reutzel, C. R. 2011. Signaling theory: A review and assessment. Journal of Management, 37: 39-67.

Connelly, B. L., Tihanyi, L., Crook, T. R., \& Gangloff, K. A. 2014. Tournament theory: Thirty years of contests and competitions. Journal of Management, 40: 16-47.

Converse, P. D., Pathak, J., DePaul-Haddock, A. M., Gotlib, T., \& Merbedone, M. 2012. Controlling your environment and yourself: Implications for career success. Journal of Vocational Behavior, 80: 148-159.

De Janasz, S. C., \& Forret, M. L. 2008. Learning the art of networking: A critical skill for enhancing social capital and career success. Journal of Management Education, 32: 629-650.

De Vos, A., De Clippeleer, I., \& Dewilde, T. 2009. Proactive career behaviours and career success during the early career. Journal of Occupational and Organizational Psychology, 82: 761-777.

Dries, N., Pepermans, R., Hofmans, J., \& Rypens, L. 2009. Development and validation of an objective intraorganizational career success measure for managers. Journal of Organizational Behavior, 30: 543-560.

Dries, N., \& Verbruggen, M. 2012. Fresh perspectives on the 'new'career: Introduction to the special section. Journal of Vocational Behavior, 81: 269-270.

Duff, A. J., \& Chan, C. C. A. 2014. Investigating suicide as a career response. Career Development International, 19: 4-26.

Eagly, A. H., \& Karau, S. J. 2002. Role congruity theory of prejudice toward female leaders. Psychological Review, 109: 573-598.

Eby, L. T., Allen, T. D., Evans, S. C., Ng, T., \& DuBois, D. L. 2008. Does mentoring matter? A multidisciplinary metaanalysis comparing mentored and non-mentored individuals. Journal of Vocational Behavior, 72: 254-267.

Feldman, D. B., Davidson, O. B., \& Margalit, M. 2015. Personal resources, hope, and achievement among college students: The conservation of resources perspective. Journal of Happiness Studies, 16: 543-560. 
Feldman, D. C., \& Ng, T. W. H. 2007. Careers: Mobility, embeddedness, and success. Journal of Management, 33: 350-377.

Ferris, G. L., Witt, L. A., \& Hochwarter, W. A. 2001. Interaction of social skill and general mental ability on job performance and salary. Journal of Applied Psychology, 86: 1075-1082.

Fletcher, T. D., Major, D. A., \& Davis, D. D. 2008. The interactive relationship of competitive climate and trait competitiveness with workplace attitudes, stress, and performance. Journal of Organizational Behavior, 29: 899922.

Folkman, S., Lazarus, R. S., Gruen, R. J., \& DeLongis, A. 1986. Appraisal, coping, health status, and psychological symptoms. Journal of Personality and Social Psychology, 50: 571-579.

Gao-Urhahn, X., Biemann, T., \& Jaros, S. J. 2016. How affective commitment to the organization changes over time: A longitudinal analysis of the reciprocal relationships between affective organizational commitment and income. Journal of Organizational Behavior, 37: 515-536.

Greenhaus, J. H., \& Kossek, E. E. 2014. The contemporary career: A work-home perspective. Annual Review of Organizational Psychology and Organizational Behavior, 1: 361-388.

Greenhaus, J. H., Parasuraman, S., \& Wormley, W. M. 1990. Effects of race on orgnizational experiences, job performance evaluations, and career outcomes. Academy of Management Journal, 33: 64-86.

Gunz, H. P., \& Heslin, P. A. 2005. Reconceptualizing career success. Journal of Organizational Behavior, 26: 105111.

Halbesleben, J. R. B., Neveu, J. P., Paustian-Underdahl, S. C., \& Westman, M. 2014. Getting to the "COR": Understanding the role of resources in conservation of resources theory. Journal of Management, 40: 1334-1364.

Hall, D. T. 2002. Careers in and out of organizations. Thousand Oaks, CA: Sage.

Hall, D. T., \& Chandler, D. E. 2005. Psychological success: When the career is a calling. Journal of Organizational Behavior, 26: 155-176.

Heilman, M. E., Wallen, A. S., Fuchs, D., \& Tamkins, M. M. 2004. Penalties for success: Reactions to women who succeed at male gender-typed tasks. Journal of Applied Psychology, 89: 416-427.

Hennekam, S. 2016. Competencies of older workers and its influence on career success and job satisfaction. Employee Relations, 38: 130-146.

Heslin, P. A. 2003. Self- and other-referent criteria of success. Journal of Career Assessment, 11: 262-286.

Heslin, P. A., Keating, L. A., \& Minbashian, A. in press. How Situational Cues and Mindset Dynamics Shape Personality Effects on Career Outcomes. Journal of Management.

Hobfoll, S. E. 1989. Conservation of resources: A new attempt at conceptualizing stress. American Psychologist, 44: 513-524.

Hobfoll, S. E. 2002. Social and psychological resources and adaptation. Review of general psychology, 6: 307-324.

Hobfoll, S. E., Halbesleben, J., Neveu, J.-P., \& Westman, M. 2018. Conservation of resources in the organizational context: The reality of resources and their consequences. Annual Review of Organizational Psychology and Organizational Behavior, 5: 103-128.

Holtschlag, C., Morales, C. E., Masuda, A. D., \& Maydeu-Olivares, A. 2013. Complementary person-culture values fit and hierarchical career status. Journal of Vocational Behavior, 82: 144-153.

Johnson, C. D., \& Eby, L. T. 2011. Evaluating career success of African American males: It's what you know and who you are that matters. Journal of Vocational Behavior, 79: 699-709.

Judge, T. A., \& Hurst, C. 2008. How the rich (and happy) get richer (and happier): Relationship of core self-evaluations to trajectories in attaining work success. Journal of Applied Psychology, 93: 849-863.

Judge, T. A., Ilies, R., \& Dimotakis, N. 2010. Are health and happiness the product of wisdom? The relationship of general mental ability to educational and occupational attainment, health, and well-being. Journal of Applied Psychology, 95: 454-468.

Judge, T. A., Kammeyer-Mueller, J., \& Bretz, R. D. 2004. A longitudinal model of sponsorship and career success: A study of Industrial-Organizational Psychologists. Personnel Psychology, 57: 271-303.

Judge, T. A., \& Kammeyer-Mueller, J. D. 2012. On the value of aiming high: The causes and consequences of ambition. Journal of Applied Psychology, 97: 758-775. 
Jung, Y., \& Takeuchi, N. 2018. A lifespan perspective for understanding career self-management and satisfaction: The role of developmental human resource practices and organizational support. Human Relations, 71: 73-102.

Kammeyer-Mueller, J. D., Judge, T. A., \& Piccolo, R. F. 2008. Self-esteem and extrinsic career success: Test of a dynamic model. Applied Psychology: An International Review, 57: 204-224.

Kats, M. M. S., Van Emmerik, H. I. J., Blenkinsopp, J., \& Khapova, S. N. 2010. Exploring the associations of culture with careers and the mediating role of HR practices: A conceptual model. Career Development International, 15: 401-418.

Keller, A. C., Spurk, D., Baumeler, F., \& Hirschi, A. 2016. Competitive climate and workaholism: Negative sides of future orientation and calling. Personality and Individual Differences, 96: 122-126.

Kirchmeyer, C. 1998. Determinants of managerial career success: Evidence and explanation of male/female differences. Journal of Management, 24: 673-692.

Korman, A. K., Wittig-Berman, U., \& Lang, D. 1981. Career success and personal failure: Alienation in professionals and managers. Academy of Management Journal, 24: 342-360.

Lee, C. I. S. G., Felps, W., \& Baruch, Y. 2014. Toward a taxonomy of career studies through bibliometric visualization. Journal of Vocational Behavior, 85: 339-351.

Lent, R. W., Brown, S. D., \& Hackett, G. 1994. Toward a unifying social cognitive theory of career and academic interest, choice, and performance. Journal of Vocational Behavior, 45: 79-122.

Liu, Y., Mo, S., Song, Y., \& Wang, M. 2016. Longitudinal analysis in occupational health psychology: A review and tutorial of three longitudinal modeling techniques. Applied Psychology: An International Rreview, 65: 379-411.

Mainiero, L. A., \& Sullivan, S. E. 2005. Kaleidoscope careers: An alternate explanation for the "opt-out" revolution. The Academy of Management Executive, 19: 106-123.

Mayrhofer, W., Briscoe, J. p., Hall, D. T., Dickmann, M., Dries, N., Dysvik, A., Kaše, R., Parry, E., \& Unite, J. 2016. Career success across the globe: Insights from the 5C Project. Organizational Dynamics, 45: 197-205.

Ng, T. W. H., Eby, L. T., Sorensen, K. L., \& Feldman, D. C. 2005. Predictors of objective and subjective career success: A meta-analysis. Personnel Psychology, 58: 367-408.

Ng, T. W. H., \& Feldman, D. C. 2014a. A conservation of resources perspective on career hurdles and salary attainment. Journal of Vocational Behavior, 85: 156-168.

Ng, T. W. H., \& Feldman, D. C. 2014b. Subjective career success: A meta-analytic review. Journal of Vocational Behavior, 85: 169-179.

Pachulicz, S., Schmitt, N., \& Kuljanin, G. 2008. A model of career success: A longitudinal study of emergency physicians. Journal of Vocational Behavior, 73: 242-253.

Park, H. I., O'Rourke, E., \& O'Brien, K. E. 2014. Extending conservation of resources theory: The interaction between emotional labor and interpersonal influence. International Journal of Stress Management, 21: 384-405.

Praskova, A., Hood, M., \& Creed, P. A. 2014. Testing a calling model of psychological career success in Australian young adults: A longitudinal study. Journal of Vocational Behavior, 85: 125-135.

Rodrigues, R. A., \& Guest, D. 2010. Have careers become boundaryless? Human Relations, 63: 1157-1175.

Seibert, S. E. 2006. Career Success. In J. H. Greenhaus and G. A. Callanan (Eds.), Encyclopedia of career development. London: Sage Publications.

Seibert, S. E., Kraimer, M. L., Holtom, B. C., \& Pierotti, A. J. 2013. Even the best laid plans sometimes go askew: Career self-management processes, career shocks, and the decision to pursue graduate education. Journal of Applied Psychology, 98: 169-182.

Seibert, S. E., Kraimer, M. L., \& Liden, R. C. 2001. A social capital theory of career success. Academy of Management Journal, 44: 219-237.

Shockley, K. M., Ureksoy, H., Rodopman, O. B., Poteat, L. F., \& Dullaghan, T. R. 2016. Development of a new scale to measure subjective career success: A mixed-methods study. Journal of Organizational Behavior, 37: 128-153.

Singh, R., Ragins, B. R., \& Tharenou, P. 2009a. What matters most? The relative role of mentoring and career capital in career success. Journal of Vocational Behavior, 75: 56-67.

Singh, R., Ragins, B. R., \& Tharenou, P. 2009b. Who gets a mentor? A longitudinal assessment of the rising star hypothesis. Journal of Vocational Behavior, 74: 11-17. 
Smith-Ruig, T. 2009. Exploring career plateau as a Multi-faceted phenomenon: Understanding the types of career plateaux experienced by accounting professionals. British Journal of Management, 20: 610-622.

Spurk, D., \& Abele, A. E. 2011. Who earns more and why? a multiple mediation model from personality to salary. Journal of Business and Psychology, 26: 87-103.

Spurk, D., \& Abele, A. E. 2014. Synchronous and time-lagged effects between occupational self-efficacy and objective and subjective career success: Findings from a four-wave and 9-year longitudinal study. Journal of Vocational Behavior, 84: 119-132.

Spurk, D., Abele, A. E., \& Volmer, J. 2015. The career satisfaction scale in context: A test for measurement invariance across four occupational groups. Journal of Career Assessment, 23: 191-209.

Stumpf, S. A. 2014. A longitudinal study of career success, embeddedness, and mobility of early career professionals. Journal of Vocational Behavior, 85: 180-190.

Stumpf, S. A., \& Tymon, W. G. 2012. The effects of objective career success on subsequent subjective career success. Journal of Vocational Behavior, 81: 345-353.

Sullivan, S. E., \& Baruch, Y. 2009. Advances in career theory and research: A critical review and agenda for future exploration. Journal of Management, 35: 1542-1571.

Sutin, A. R., Costa, P. T., Miech, R., \& Eaton, W. W. 2009. Personality and career success: Concurrent and longitudinal relations. European Journal of Personality, 23: 71-84.

Ten Brummelhuis, L. L., \& Bakker, A. B. 2012. A resource perspective on the work-home interface: The work-home resources model. American Psychologist, 67: 545-556.

Tonidandel, S., LeBreton, J. M., \& Johnson, J. W. 2009. Determining the statistical significance of relative weights. Psychological Methods, 14: 387-399.

Turban, D., \& Dougherty, T. 1994. Role of protégé personality in receipt of mentoring and career success. Academy of Management Journal, 37: 688-702.

Turner, R. J. 1960. Sponsored and contest mobility and the school system. American Sociological Review of Educational Research, 25: 855-867.

Valcour, M., \& Ladge, J. J. 2008. Family and career path characteristics as predictors of women's objective and subjective career success: Integrating traditional and protean career explanations. Journal of Vocational Behavior, 73: 300-309.

Van den Born, A., \& Witteloostuijn, A. 2013. Drivers of freelance career success. Journal of Organizational Behavior, 34: 24-46.

Van der Heijden, B. I. J. M., De Lange, A. H., Demerouti, E., \& Van der Heijde, C. M. 2009. Age effects on the employability-career success relationship. Journal of Vocational Behavior, 74: 156-164.

Van Dierendonck, D., \& Van der Gaast, E. 2013. Goal orientation, academic competences and early career success. Career Development International, 18: 694-711.

Verbruggen, M., Van Emmerik, H., Van Gils, A., Meng, C., \& de Grip, A. 2015. Does early-career underemployment impact future career success? A path dependency perspective. Journal of Vocational Behavior, 90: 101-110.

Wang, M., \& Wanberg, C. R. 2017. 100 years of applied psychology research on individual careers: From career management to retirement. Journal of Applied Psychology, 102: 546-563.

Wayne, S. J., Liden, R. C., Kraimer, M. L., \& Graf, I. K. 1999. The role of human capital, motivation and supervisor sponsorship in predicting career success. Journal of Organizational Behavior, 20: 577-595.

Westman, M., \& Etzion, D. 1990. The career success/personal failure phenomenon as perceived in others: Comparing vignettes of male and female managers. Journal of Vocational Behavior, 37: 209-224.

Wu, P.-C., Foo, M.-D., \& Turban, D. B. 2008. The role of personality in relationship closeness, developer assistance, and career success. Journal of Vocational Behavior, 73: 440-448.

Zacher, H. 2015a. Daily manifestations of career adaptability: Relationships with job and career outcomes. Journal of Vocational Behavior, 91: 76-86.

Zacher, H. 2015b. Successful aging at work. Work, Aging and Retirement, 1: 4-25. 
Table 1

Overview of Career Success Study Characteristics ( $k=266$ Studies)

Study Characteristics

$k \quad$ Ratio

Study includes explicit hypotheses

$234 \quad 88.0 \%$

Study measures career success

Objective career success

$71 \quad 26.7 \%$

Subjective career success

$75 \quad 28.2 \%$

Both

$120 \quad 45.1 \%$

If both, differential hypotheses OCS versus SCS are made

$22 \quad 8.3 \%$

Study compares different theoretical approaches/antecedent

classes when predicting career success

$23 \quad 8.6 \%$

Study includes only antecedents

$228 \quad 85.7 \%$

Study includes only outcomes

$7 \quad 2.6 \%$

Study includes both antecedents and outcomes

$31 \quad 11.7 \%$

If both, reciprocal causal relations are tested

$5 \quad 1.9 \%$

Study tests mediator effects

$92 \quad 34.6 \%$

Study tests moderator effects

$94 \quad 35.3 \%$

Cross-sectional study

$175 \quad 65.8 \%$

Longitudinal study

$91 \quad 34.2 \%$

If yes, career success change analysis is performed

$37 \quad 13.9 \%$

If yes, change analysis for outcomes of career success

$6 \quad 2.3 \%$ 
Table 2

Taxonomy of Theoretical Approaches Used in Studies of Antecedents of Career Success $(k=259$ Studies $)$

\begin{tabular}{|c|c|c|c|c|c|c|}
\hline Theoretical Approach Categories & Sample Theoretical Approaches and Related Articles ${ }^{1}$ & Sample Antecedents & $k(\%$ studies $)$ & $k_{\mathrm{OCS}}$ & $k_{\mathrm{SCS}}$ & kOCS/SCS \\
\hline Personal Resources & & & $104(40.2 \%)$ & 42 & 17 & 45 \\
\hline $\begin{array}{l}\text { 1. Human Capital } \\
\text { Theoretical approaches that focus on } \\
\text { how an individual's work-related } \\
\text { knowledge, skills, and competences } \\
\text { affect career success }\end{array}$ & $\begin{array}{l}\text { - Human Capital Theory (Baruch \& Lavi-Steiner, 2015) } \\
\text { - General Mental Ability (Judge et al., 2010) } \\
\text { - Allocation of Energy Model (Judiesch \& Lyness, 1999) }\end{array}$ & $\begin{array}{l}\text { education, general mental } \\
\text { ability, childhood socio- } \\
\text { economic status }\end{array}$ & $55(21.2 \%)$ & 21 & 4 & 30 \\
\hline $\begin{array}{l}\text { 2. Roles and Identity } \\
\text { Theoretical approaches that focus on } \\
\text { how an individual's understanding of } \\
\text { his or her personal and social roles, } \\
\text { or the belongingness to specific roles } \\
\text { across different life domains affect } \\
\text { career success }\end{array}$ & $\begin{array}{l}\text { - Identity Theory (Grote and Raeder, 2009) } \\
\text { - Gender Role Theory (Parasuraman, 1996) } \\
\text { - Cognitive Dissonance Theory (Mayrhofer et al., 2008) }\end{array}$ & $\begin{array}{l}\text { gender, continuous } \\
\text { identity, family and work } \\
\text { involvement }\end{array}$ & $43(16.6 \%)$ & 16 & 12 & 15 \\
\hline $\begin{array}{l}\text { 3. (Competitive) Performance } \\
\text { Theoretical approaches that focus on } \\
\text { how the (relative) performance } \\
\text { level/rank of an individual affects } \\
\text { career success }\end{array}$ & $\begin{array}{l}\text { - Tournament Theory (Hurley et al., 2003) } \\
\text { - Contest Mobility Perspective (Cheung et al., 2016) } \\
\text { - Big Fish Little Pond Effect (Higgins et al., 2008) }\end{array}$ & $\begin{array}{l}\text { late career entry, task } \\
\text { performance, getting- } \\
\text { ahead career orientation, } \\
\text { problem solving }\end{array}$ & $29(11.2 \%)$ & 12 & 4 & 13 \\
\hline Proximal Environmental Resources & & & $109(42.1 \%)$ & 36 & 27 & 46 \\
\hline $\begin{array}{l}\text { 4. Social Environment } \\
\text { Theoretical approaches that focus on } \\
\text { how the social surroundings and/or }\end{array}$ & $\begin{array}{l}\text { - Social Capital Theory (Seibert et al., 2001) } \\
\text { - Social Exchange Theory (Harris et al., 2006) }\end{array}$ & $\begin{array}{l}\text { network structure (weak } \\
\text { ties, structural holes), }\end{array}$ & $88(34.0 \%)$ & 26 & 19 & 43 \\
\hline
\end{tabular}


support experienced by an individual affect career success

- Signaling Theory (Dougherty et al., 2013)

- Sponsored Mobility Perspective (Wayne et al., 1999)

- Procedural Justice Theory (Ngo \& Li, 2015)

- HRM Climate Strength (Stumpf et al., 2010)

- Internal Labor Market Theory (Nabi, 2003)

environment (i.e., job, workplace,

and/or organizational characteristics)

affect career success

\section{Resource Management Behaviors and Attitudes}

\section{Career Agency}

Theoretical approaches that focus on how an individual's work attitudes, career management, and proactive behaviors affect career success

- Political Skill Theory (Blickle et al., 2012)

- Protean Career Model (Briscoe et al., 2012)

- Boundaryless Career Model (Eby et al., 2003)

- Social-Cognitive Career Theory (Spurk \& Abele, 2014)

- Conservation of Resources Theory (Grimland et al., 2012)

- Expansion Model of Human Energy (Dikkers et al., 2010)

- Stress and Coping Process Model (Armstrong-Strassen, 2003) career success leader-member-

exchange, different types

of mentoring

procedural justice,

$29(11.2 \%)$

perceived effectiveness of HRM-practices, firm type, career prospects,

job security

$$
82(31.7 \%) \quad 10 \quad 30
$$

political skills, career

$71(27.4 \%)$ 8

adaptability,

boundaryless mindset,

self-directed career

management, feedback-

seeking behavior

social stressors, flexible arrangements, work

hours, pre- and post-job

rank after downsizing 


\section{Personal Key Resources}

\section{Stable Traits}

Theoretical approaches that focus on how (assumed to be) stable personality characteristics affect career success

\section{Contextual Macro Resources}

- Big Five Personality Model (Seibert \& Kraimer, 2001) - RIASEC Model (Spurk et al., 2014)

- Incentive-Enhancing Property of Personality (Zhang \& Arvey, 2009)

\section{National Culture}

Theoretical approaches that focus on how national culture or experienced cultural characteristics affects an individual's career success

\section{Resource Accumulation and Dynamics}

- Hofstede's Theory of National Values (Moon \& Choi, 2017)

- Schwartz's Theory of Basic Human Values (Holtschlag et al., 2013)
10. Person-Environment Interactions Theoretical approaches that focus on how the interplay between an individual's characteristics (e.g., skills, personality, interests) and those of the environment affect career success

\section{Lifespan}

Theoretical approaches that focus on how the progression of an individual through different life or career stages affects career success
- Person-Environment Fit Theory (Erdogan \& Bauer, 2005)

- Reinforcement Theory (Bretz \& Judge, 1994)

- Attraction-Selection-Attrition Theory (Erdogan et al., 2004)

- Labeling Theory (Verbruggen et al., 2015)

- Aging Theory (Bal et al., 2015)

- Selection-Optimization-Compensation Model (Abele \& Wiese, 2008)
Big Five, occupational group membership, achievement motive, locus of control

self-enhancement-, hierarchy-, and egalitarian values

person-job and person$35(13.5 \%)$ organization fit, workvalue congruence, underemployment

age, selection, optimization, career stage, generation, goal engagement 
- Theory of Career Stage Development (Clark \& Arnold, 2008)

\section{Career Transitions}

Theoretical approaches that focus on

- International Career Logics Typology (Andresen \& Biemann, 2013)

how specific career transitions (e.g., organizational mobility, occupational mobility) affect career success

- Career Interruption Penalties (Reitman \& Schneer, 2005)

- Career Mobility Models (Valcour \& Tolbert, 2003)

\section{Other}

13. Hybrid

Theoretical approaches that mix together several aspects of the above approaches to studying career success

- Intelligent Career Model (Van de Born and Witteloostuijn, 2013)

- Kaleidoscope Career Model (Karren \& Gowan, 2012)

- Career Capital Theory (Singh et al., 2009a)

\section{Single Occurrences}

Theoretical approaches that could not be clearly categorized into any of the above categories and represent single occurrences of a theory
- Labor Market Segmentation Theory (Kovalenko \& Mortelmans, 2014)

- Theory of Proportional Representation (Kirchmeyer, 1998)

- Balance Theory (Wu et al., 2013) career history,

$9(3.5 \%)$ 2

employment gaps, intraand inter-organizational mobility

career insight, career

calling, autonomy,

flexibility, career capital

transitional versus ittern and employee and supervisor political skills

Note. Across the 259 studies, 559 distinct theoretical approaches were coded in this taxonomy. ${ }^{1}$ References that only appear in this table are listed in Supplemental Material 1. 
Table 3

Overview of Studies and Taxonomy of Outcomes of Career Success ( $k=25$ Studies)

\begin{tabular}{ll} 
Outcomes of Career Success & Sample Theoretical Approaches and Related Articles ${ }^{1}$ \\
& \\
\hline $\begin{array}{l}\text { 1. Withdrawal } \\
\text { Cognitions or behaviors directed }\end{array}$ & - Social Cognitive Career Theory (Shockley et al., 2016) \\
$\begin{array}{l}\text { toward leaving the job, } \\
\text { organization, } \text { or occupation }\end{array}$ & - Inducement Contribution Model (Tremblay et al., 2014) \\
$\begin{array}{l}\text { (e.g., actual turnover or } \\
\text { retirement intentions) }\end{array}$ & - Theory of Planned Behavior (Hofstetter \& Cohen, 2014)
\end{tabular}

2. Career Attitudes

Individual attitudes related to the work and/or career domain (e.g., career self-efficacy beliefs or career calling)

3. Well-Being and Health Objective or subjective indicators of an individual's physical or mental well-being

- Social Cognitive Career Theory (Spurk \& Abele, 2014)

- Calling Model of Success (Praskova at al., 2014)

- Reflection Theory of Compensation (Gao-Urhahn et al., 2016)

- Social Exchange Theory (Moon \& Choi, 2017)

- Identity Perspectives (Gao-Urhahn et al., 2016)

- Career Construction Theory (Zhou et al., 2016)

- Self-Determination Theory (Zhou et al., 2016)

No theoretical approaches mentioned explicitly; mainly empirical reasoning

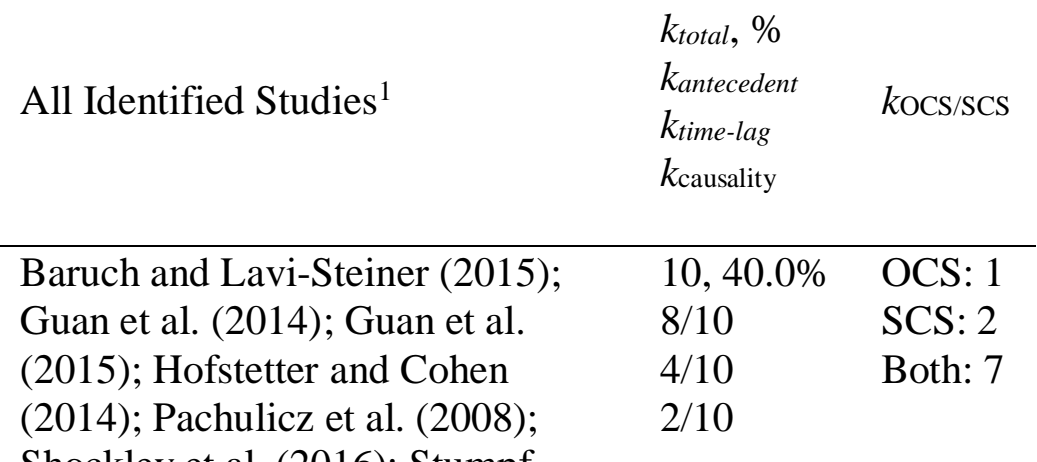

Shockley et al. (2016); Stumpf

(2014); Taylor et al. (1996);

Tremblay et al. (2014); Tymon et al. (2011)

Baruch and Lavi-Steiner (2015); Gao-Urhahn et al. (2016); Moon and Choi (2017); Park (2009); Praskova et al. (2014); Shockley et $\quad 3 / 9$ al. (2016); Spurk and Abele (2014); Taylor et al. (1996); Zhou et al. (2016)

Chen et al. (2008); Judge and Kammeyer-Mueller (2012); Judge 6, $24.0 \%$ et al. (2010a); Leung et al. (2011);
OCS: 2

SCS: 4 Both: 3

OCS: 2 SCS: 2 Both: 2
$4 / 6$

$2 / 6$
$0 / 6$ 
and health (e.g., depression or

mortality)

4. Reactions from the (Work)

Environment

Reaction of other individuals from the work or nonwork domain to an individual's career success (e.g., obtained mentoring or failure perceptions)

\section{Self-Concept}

Generalized self-perceptions about personal characteristics or attributes (e.g., self-esteem or core self-evaluation)
Russo et al. (2014); Shockley et al. (2016)

- Anchoring and Consistency (Stumpf \& Tymon, 2012)

- Rising Star Hypothesis (Singh et al., 2009b)

- Career Success/Personal Failure Phenomenon (Westman \& Etzion, 1990)

Singh et al. (2009b); Stumpf and Tymon (2012); Westman and $3,12.0 \%$ $0 / 3$

OCS: 3

Tymon $(20$ $1 / 3$

SCS: 0

Etzion (1990)

Kammeyer-Mueller et al. (2008);

$2,8.0 \%$

- Attribution Theory (Stumpf \& Tymon, 2012)

Stumpf and Tymon (2012)

$2 / 2$

OCS: 2

- Anchoring and Consistency ((Stumpf \& Tymon, 2012)

- Social Identity Theory (Kammeyer-Mueller et al., 2008)

- Functional Role Theory (Kammeyer-Mueller et al., 2008)

Note. ${ }^{1}$ References are listed in Supplemental Material 1. \% in relation to $k=25 . k_{\text {antecedent }}=$ number of studies that also analyzed antecedents of career success (i.e., career success was a mediator, or a reciprocal model was tested). $k_{\text {time-lag }}=$ number of studies that had a time lag between career success and the outcomes. $k_{\text {causality }}=$ number of studies that applied a design that allowed for causal inference. $k$ OCS/SCS $=$ number of studies that analyzed OCS only, SCS only, or both. 